patients attending mini clinics also attended the hospital clinic, and these were mainly young diabetics or those with complications. Patients attending mini clinics represent the true spread of diabetes in the community, and the proportion who default is considerably smaller than that among patients attending the hospital clinic. ${ }^{8}$

We emphasise that the patients in this study were a random sample. They were not chosen in order to show improved metabolic control, and it is clear from table II that control was not ideal. The aim of our study was to assess glycaemic control in patients routinely managed in mini clinics by comparing them with those attending a hospital clinic. We selected patients who were well matched for age, sex, race, weight, and duration of diabetes. For all treatment groups we found no significant differences in retrospective mean blood glucose concentrations, retrospective $\mathrm{HbA}_{1}$ concentrations, or prospective $\mathrm{HbA}_{1}$ concentrations. We conclude that the mini clinics achieve the same degree of metabolic control in their diabetic patients as the hospital clinic.

We thank Dr A G Jacobs, the staff in the clinical chemistry department, and Miss L Butterworth, who gave many hours of administrative and secretarial help. This study would have been impossible without the help of the mini clinic general practitioners. We are also grateful to the Rotha Abraham Trust for providing financial support.

\section{References}

1 Doney BJ. An audit of the care of diabetes in a group practice. $f R$ Coll Gen Pract 1976;26:734-42.

Pract Ap. An audit of the care of diabetics in one general practice. $\mathcal{f} R$ Coll Gen Pract 1977;27:536-43.

letcher BRG. Looking after diabetics in general practice: a trainee project. $f R$ Coll Gen Pract 1977;27:85-8.

等 22:309-14.

5 Dornan C, Fowler G, Mann JI, Markus A, Thorogood M. A community study of diabetes in Oxfordshire. $\mathcal{F} R$ Coll Gen Pract 1983;33:151-5.

6 Wilkes E, Lawton EE. The diabetic, the hospital and primary care. $\mathcal{F} R$ Coll Gen Pract 1980;30:199-206.

Hill RD. Community care service for diabetics in the Poole area. $\mathrm{Br}$ Med $\mathrm{f}$ $1976 ;$; :1137-9.

Thorn PA. Care for diabetics in the United Kingdom. In: Mann JI, Pyörälä K, Teuscher A, eds. Diabetes in epidemiological perspective. Edinburgh: Churchil Livingstone, 1983:305-14

Thorn PA, Russell RG. Diabetic clinics today and tomorrow: mini clinics in general practice. Br Med $\mathcal{F} 1973$;ii:534-6.

, Tyler LE. Diabetic clinics in general practice. Update $1974 ; 8: 945$

1951-52;16:316-34

12 Conover WJ, ed. Practical non parametric statistics. New York: Wiley, 1971.

Gabbay KH, Hasty K, Breslow JL, Ellison RC, Bunn FH, Gallop PM. Glycosylated haemoglobins and long term blood glucose control in diabetes mellitus. f Clin Endocrinol Metab 1977;44:859-64.

14 Paisey RB, Bradshaw P, Hantog M. Home blood glucose concentrations in maturity onset diabetes. $B r M e d ~ \mathcal{F} 1980 ; \mathrm{i}: 596-8$.

15 Walford S. Diabetic control. University of Cambridge, 1984. $251 \mathrm{pp}$. (MD thesis.) Thobroutsky G, Charitanski D, Blouquit Y, Papoz L, Soria J, Rosa J. Diabetic control in 102 insulin treated outpatients. Diabetologia 1980;18:447-52.

17 Muir A, Howe-Davies SA, Turner RC. General practice care of non insulin 73:637-40.

(Accepted 4 fune 1984)

\title{
Randomised controlled trial of routine hospital clinic care versus routine general practice care for type II diabetics
}

\author{
T M HAYES, J HARRIES
}

\begin{abstract}
Two hundred patients with type II diabetes were entered into a randomised controlled trial lasting five years to compare routine care of this condition by a hospital diabetic clinic with routine care in general practice. Fewer patients in the group being cared for by their general practitioner (general practice group) were regularly reviewed or had regular estimations of blood glucose concentration. More patients in the general practice group than in the hospital group were admitted to hospital for medical reasons during the study (25 (24\%) compared with $17(18 \%))$ and more patients in the general practice group died (18) than did in the hospital group (6). At the end of the study mean concentrations of haemoglobin $A_{1}$ were higher in the general practice group $(10.4 \%)$ than in the hospital group (9.5\%).

Routine care in general practice for patients with type II diabetes was less satisfactory than care by the hospital diabetic clinic.
\end{abstract}

\footnotetext{
Diabetic Unit, Department of Medicine, University Hospital of Wales, Cardiff CF4 4XW

$T$ T HAYES, FRCP, consultant physician

J HARRIES, MRCGP, general practitioner, clinical assistant

Correspondence to: Dr T M Hayes.
}

\section{Introduction}

Although there is general agreement that certain groups of patients with diabetes (pregnant women, children and adolescents, unstable and complicated patients) should regularly attend hospital diabetic clinics, much argument remains concerning the best way to provide continuing care for the remaining majority of diabetics. This is particularly so for patients with uncomplicated type II diabetes. Many diabetic clinics think that within their present resources they cannot provide the standard of care they consider desirable for every diabetic patient and wish to concentrate their resources on those whom they think most need the facilities of the clinic, leaving the remainder to be cared for by their general practitioners. General practitioners, ${ }^{1}$ the editor of the British Medical fournal, ${ }^{2}$ and many patients think that most diabetics should be looked after in general practice with the clinic concentrating on difficult problems. Another group of general practitioners, however, thinks that all diabetics should have their disorder supervised by a specialist clinic, and many clinics have a policy of not discharging any patients. This view is supported by a report from the Royal College of Physicians, ${ }^{3}$ though this has been challenged. ${ }^{4}$

We examined in a randomised controlled trial the argument that patients with uncomplicated type II diabetes could be as well looked after in general practice as in a hospital clinic. Patients in this study were randomly allocated to either continued attendance at a hospital clinic or discharge back to the care of their general practitioner.

\section{Patients and methods}

Initial meetings were held, at which general practitioners from the area (a mixed urban and rural area with an average list size of 2100) 
chosen for the study were invited to discuss both the proposed study and the principles of continuing diabetic care. All the general practitioners were circulated with written details of the study and given the opportunity to opt out; two practices declined to participate. After these initial meetings no postgraduate education over and above that normally available - that is, a minimum of one session on diabetes for general practitioners each year-was provided.

Two hundred patients with type II diabetes aged from 40 to 80 were chosen from the diabetic clinics of this hospital. They were selected on the basis that they resided in the area where general practitioners had agreed to take part in the study; they agreed to be discharged back to their general practitioner if necessary, and they were free of diabetic complications or other diseases necessitating continued hospital attendance. Patients were not excluded from the trial if they showed very early background retinopathy, minor degrees of asymptomatic peripheral neuropathy, absence of one pedal pulse without clinical evidence of ischaemia, or intermittent albuminuria without a raised blood urea concentration. All the patients had had their treatment regimens optimised in the diabetic clinic to give reasonable diabetic control and they had all received dietary education.

After selection the patients were randomly allocated, using sealed envelopes prepared by the Medical Research Council Epidemiology Unit (South Wales), to either continued attendance at the diabetic clinic or discharge to the continuing care of their general practitioner. Those patients who continued to attend the diabetic clinic followed the usual routine of the clinic, received no special attention, did not have their case sheets identified, and saw a variety of doctors in the clinic.

Those allocated to the care of their general practitioner were told that from now on their diabetes would be supervised by him and they should attend his surgery within the next four months. A letter was sent to the general practitioner explaining that the patient was now discharged to his care from the diabetic clinic. The clinic was available for consultation if the general practitioner thought this was necessary, and open access to the hospital laboratory and dietetic and chiropody services was available. A leaflet giving guidelines for the continuing care of diabetics plus a specially designed record card were enciosed with each letter of discharge. The leaflet advised that patients should be seen at least once every six months, should be weighed, and should have their blood glucose concentrations measured and their urine examined for glucose and albumin. At least once a year their retinas should be examined, their blood pressure measured, and their feet inspected.

Five years after randomisation all the patients were reviewed in the diabetic clinic. During the five years the progress of the study was monitored by specially employed part time health visitors. These were not the same health visitors as those attached to the routine diabetic clinic and they took no part in the management of the patients. They collected information from the patients at intervals of six months concerning how often they had been seen by a doctor or clinic and whether they had any problems with their diabetes (informing the general practitioner with both groups of patients and the hospital with the group randomised to clinic care) and in the last six months of the study they took blood for assessment of haemoglobin $A_{1}$ concentrations from patients in both groups. The result of this test was not filed in the case sheet until the end of the study.

At entry into the study, a standardised physical examination was performed and blood taken for assessment of blood glucose, urea, and electrolyte concentrations; liver function tests, electrocardiography (subsequently Minnesotta coded), and fundal photography were performed; and haemoglobin $A_{1}$ concentration was measured by a column chromatography technique.

\section{Results}

Ninety seven patients (42 women) were randomly allocated to continuing care by the hospital clinic (hospital group) and 103 (40 women) were discharged to the care of their general practitioner (general practice group). Table I shows the characteristics of the two groups with particular reference to cardiovascular risk factors. At entry into the study 49 patients in each group $(47.6 \%$ in the general practice group and $50.5 \%$ in the hospital group) were receiving treatment with diet alone, and the remainder were receiving oral hypoglycaemic treatment in addition to their diet. Twenty two patients $(21.4 \%)$ in the general practice group and $19(19.6 \%)$ in the hospital group were taking biguanides either alone or in combination with sulphonylureas; the remainder were taking sulphonylureas alone.

During the study only $14(13.6 \%)$ of the patients in the general practice group were regularly reviewed (at least once a year) for their diabetes and only five $(4.8 \%)$ in this group had blood glucose concen-
TABLE I-Characteristics of patients randomly allocated to care by either the hospital clinic or their general practitioner

\begin{tabular}{|c|c|c|}
\hline & $\begin{array}{c}\text { General practice } \\
\text { group } \\
(\mathrm{n}=103)\end{array}$ & $\begin{array}{l}\text { Hospital group } \\
\qquad(\mathrm{n}=97)\end{array}$ \\
\hline \multirow{2}{*}{$\begin{array}{l}\text { Mean (SD) age (years) } \\
\text { No }(\%) \text { with history of ischaemic heart disease } \\
\text { No }(\%) \text { with abnormal lipids } \\
\text { No }(\%) \text { smoking: } \\
1-20\end{array}$} & $\begin{array}{c}59 \cdot 7(7 \cdot 1) \\
9(8 \cdot 4) \\
25(24 \cdot 2)\end{array}$ & $\begin{array}{c}58 \cdot 4(9 \cdot 3) \\
5(5 \cdot 6) \\
26(26 \cdot 8)\end{array}$ \\
\hline & $\begin{array}{l}22(21 \cdot 2) \\
16(15 \cdot 1)\end{array}$ & $\begin{array}{l}23(23.5) \\
10(10.3)\end{array}$ \\
\hline \multirow{2}{*}{$\begin{array}{l}>20 \\
\text { No }(\%) \text { at entry with electrocardiogram: } \\
\text { Normal } \\
\text { Borderline } \\
\text { Abnormal } \\
\text { No ( } \%) \text { obese* } \\
\text { Mean (SD) blood pressure (mm Hg): } \\
\text { Systolic } \\
\text { Diastolic }\end{array}$} & $\begin{array}{l}77(75) \\
21(20) \\
5(5) \\
31(30 \cdot 3)\end{array}$ & $\begin{array}{l}55(57) \\
29(30) \\
13(13) \\
37(38 \cdot 1)\end{array}$ \\
\hline & $\begin{array}{r}152(20) \\
89(10)\end{array}$ & $\begin{array}{r}156(28) \\
90(12)\end{array}$ \\
\hline
\end{tabular}

* Over $110 \%$ ideal body weight.

TABLE II-Changes in category of treatment. Values are numbers (\%) of patients

\begin{tabular}{|c|c|c|c|}
\hline Initial treatment & Final treatment & $\begin{array}{c}\text { General practice } \\
\text { group } \\
(\mathbf{n}=103)\end{array}$ & $\begin{array}{c}\text { Hospital group } \\
(\mathbf{n}=97)\end{array}$ \\
\hline Diet only & $\begin{array}{l}\text { Oral hypoglycaemic } \\
\text { treatment } \\
\text { Insulin }\end{array}$ & ${ }_{1}^{11}(10 \cdot 0)$ & $\begin{array}{l}9(9 \cdot 3) \\
1(1 \cdot 0)\end{array}$ \\
\hline $\begin{array}{l}\text { Oral hypoglycaemic } \\
\text { treatment }\end{array}$ & $\begin{array}{l}\text { Diet } \\
\text { Insulin }\end{array}$ & $\begin{array}{l}1(1 \cdot 0) \\
3(2 \cdot 9)\end{array}$ & $\begin{array}{l}4(4 \cdot 1) \\
2(2 \cdot 1)\end{array}$ \\
\hline Total changed & & $16(15 \cdot 5)$ & $16(16.5)$ \\
\hline
\end{tabular}

TABLE III-Reasons for admission to hospital during the study. Values are numbers $(\%)$ of patients admitted

\begin{tabular}{lcc}
\hline & $\begin{array}{c}\text { General practice } \\
\text { group } \\
(\mathrm{n}=103)\end{array}$ & $\begin{array}{c}\text { Hospital group } \\
(\mathrm{n}=97)\end{array}$ \\
\hline Diabetes & $7(6 \cdot 8)$ & $5(5 \cdot 1)$ \\
Cardiovascular & $15(14 \cdot 6)$ & $10(10.3)$ \\
Surgical operations & $10(9 \cdot 7)$ & $11(11 \cdot 3)$ \\
Others & $3(2 \cdot 9)$ & $3(3 \cdot 1)$ \\
\hline Total & $35(33 \cdot 9)$ & $29(29 \cdot 9)$ \\
\hline
\end{tabular}

TABLE IV-Causes of death

\begin{tabular}{lcc}
\hline & $\begin{array}{c}\text { General practice } \\
\text { group } \\
(\mathrm{n}=103)\end{array}$ & $\begin{array}{c}\text { Hospital group } \\
(\mathrm{n}=97)\end{array}$ \\
\hline Cerebrovascular & 2 & 0 \\
Myocardial infarction & 10 & 3 \\
Neoplasms & 3 & 2 \\
Other & 3 & 1 \\
\hline Total & 18 & 6 \\
\hline
\end{tabular}

tration measured at least once a year. Those who attended the hospital clinic were seen at least once a year and had blood glucose concentration measured. Three patients in the hospital group and nine in the general practice group were lost to follow up. The haemoglobin $A_{1}$ concentration at the end of the study was mean (SD) $10.4(1.73) \%$ in the general practice group and $9.5(1.77) \%$ in the hospital group $(t=2.52, \mathrm{p}<0.02)$.

During the study $32(31 \%)$ of the general practice group and 55 $(57 \%)$ of the hospital group had their treatment changed; in three patients in the hospital group and four in the general practice group treatment with insulin was started. Sixteen patients in each group changed the form of their treatment (table II). Forty five patients $(44 \%)$ in the general practice group and $36(37 \%)$ in the clinic group thought that they had problems with their diabetes during the five years of the study. Twenty five patients $(24 \%)$ in the general practice group and $17(18 \%)$ in the hospital group were admitted to hospital for medical reasons at least once during the trial. If surgical operations are included the respective figures rise to $35(24 \%)$ and $29(30 \%)$. Table III gives the reasons for admission to hospital.

Eighteen patients in the general practice group died as did six in the hospital group; table IV shows the certified causes of death. The difference between the two groups was significant $\left(\chi^{2}=5 \cdot 642\right.$; $\mathrm{p}<0.02)$. 


\section{Discussion}

If patients with uncomplicated type II diabetes could be as satisfactorily looked after in general practice as in hospital clinics for diabetics, patients (by avoiding the time taken and finance incurred in attending the clinic), general practitioners (by maintaining the continuity of care of patients), and hospital clinics (by having more time available to see more complicated problems) would benefit. This study, however, shows that routine care by general practitioners is not as satisfactory as routine care by hospital clinics. One reason for this is that general practitioners often do not have at hand the facilities that are considered to be essential in any diabetic clinic. Dietetic advice, chiropody, rapid access to laboratory and radiographic services, though available, are not immediately to hand. Possibly most important is the absence in most general practices of an automatic recall system for patients who do not attend. This may well account for the low number of patients who were regularly reviewed by their general practitioner. In addition, most practices are not geared to giving people definite appointments for review four or six months later.

There have been several successful attempts at helping general practitioners to care for diabetic patients. These schemes fall into two categories: firstly, there is the miniclinic system, which has been described by Thorn ${ }^{5}$ and in which general practitioners are encouraged to set up miniclinics within their practice, often with one partner taking a particular interest in diabetics; secondly, there are shared care schemes, such as that described by $\mathrm{Hill}^{6}{ }^{6}$ in which the hospital clinic sees the patients rarely but provides a hospital based blood sugar assay service with recall of patients who do not attend. Some of these schemes now also measure glycosylated haemoglobin concentration and use ophthalmic opticians to screen for diabetic retinopathy.? Although these schemes have proved successful in certain centres they need considerable organisation.

Our study shows that the simple transfer of responsibility for continuing care from hospital clinics to general practice is unlikely to maintain an adequate standard of care. The need, however, to discharge patients back to their general practitioners remains. Evidently, careful planning will be needed before diabetics can be satisfactorily transferred back to the care of their general practitioner. Different patterns of shared care (including miniclinics where appropriate) may prove satisfactory in different areas. The clinics continue to play an important part as a focus for expertise to which general practitioners can rapidly turn; some centres may provide "review clinics," at intervals of one to two years, at which patients are thoroughly reassessed, and in between these visits patients have their diabetes monitored and treatment adjusted by their general practitioner.

Although any one system is unlikely to achieve nationwide success, a computerised system similar to that used for follow up of patients with thyroid abnormalities in many parts of the United Kingdom may be worthy of further study. This would recall the patients to see their general practitioner at regular intervals, warn him, and request him to collect both clinical information and blood for estimation of glycosylated haemoglobin concentration. General practitioners would be relieved of the necessity of having a complicated recall system and would be prompted to take appropriate clinical action by the computer print out. Such a system is under active consideration or development in a number of areas including our own.

We thank Professor A Cochrane for advice and support in setting up this study. The trial was financed by a grant from the Office of the Chief Scientist, Department of Health and Social Security.

\section{References}

1 Wilks JM. Diabetes-a disease for general practice. $\mathcal{f} R$ Coll Gen Pract 1973;23: 46-54.

2 Anonymous. Open letter to the new CMO [Editorial]. Br Med f 1983;287:1903-5. Standing Committee on Endocrinology and Diabetes Mellitus of the Royal London: Royal College of Physicians, 1977.

5 Anonymous. Diabetes-who cares ? [Editorial]. Update 1977;15:455. general practice. $\mathrm{Br}$ Med $\mathcal{F} 1973 ; \mathrm{ii}: 534-6$.

6 Hill RD. Community care service for diabetics in the Poole area. Br Med 7 1976; i:1137-9.

7 Gilbert CE, Armstrong S, Burns-Cox C, Hart JCD. Screening of diabetics by ophthalmic opticians. Trans Ophthalmol Soc UK 1982;102:249-52.

(Accepted 20 fuly 1984)

\section{SHORT REPORTS}

\section{Kingella kingae septicaemia with a clinical presentation resembling disseminated gonococcal infection}

We report the first case in Britain of an adult with pyrexia of undetermined origin and clinical features suggesting disseminated gonococcal infection $^{1}$ but in whom the cause was septicaemia due to Kingella kingae.

\section{Case report}

A previously healthy English woman, aged 21, was admitted on 7 February 1984 with a 10 day history of fever, malaise, and fleeting aches in the joints of the fingers, toes, ankles, and hips. Two weeks before her illness she had returned from a holiday visiting Florida and the Bahamas. She denied having had any sexual intercourse since October 1983. On admission she looked unwell, her temperature was $38.9^{\circ} \mathrm{C}$, and there were sparse petechial lesions on her right thumb, lett forefinger, and right big toe. During the next five days she developed rigors each night and new purple, 1-2 mm vasculitic skin lesions on the soles of her feet and other fingers, which were painful only at the time of their onset. On 10 February she had acute pleuritic pain in the left hypochondrium and tenderness in the left costal margin, which suggested either a splenic infarct or a splenic abscess.

On investigation the haemoglobin concentration was $11.0 \mathrm{~g} / \mathrm{dl}$, the white cell count was $23.6 \times 10^{9} / 1$ (predominantly polymorphs), and five sets of blood cultures yielded negative results. Numerous specific serological tests yielded negative results. Urethral and cervical cultures for gonococci were negative, and various scanning techniques failed to show any focus of infection.
Increased complement concentrations (haemolytic complement $200 \%$ of normal and C3 $136 \%$ of normal) and circulating immune complexes were shown in the serum by Professor Mowbray at St Mary's Hospital.

Her condition worsened, and a two week course of blind antibiotic treatment was started on 12 February with oxytetracycline $500 \mathrm{mg}$ given by mouth once every six hours. Within 24 hours there was a noticeable improvement and she became afebrile. During the subsequent week her condition continued to improve but she had two further transient attacks of myalgia and arthritis affecting her toes. She was discharged home feeling well on 23 February. One week later she developed intermittent claudication in the left leg; the peripheral pulses were no longer palpable on the left side. These symptoms resolved during April, but the pulses remained absent.

After her discharge from hospital the last blood culture, collected on 12 February just before the start of tetracycline treatment, yielded growth of a fastidious Gram negative diplobacillus, which was $\beta$ haemolytic, oxidase positive, catalase negative, and grew best on blood or chocolate agar incubated aerobically in a $10 \%$ carbon dioxide atmosphere. This organism was isolated only after 16 days' incubation of the carbon dioxide blood culture broth and was sensitive to tetracycline and penicillin. It was finally identified as $K$ (Moraxella) kingae. A serum sample collected three weeks after the onset of her illness showed a fluorescence antibody titre of $1 / 1600$ against her blood culture isolate containing kingellae, and countercurrent immunoelectrophoresis of the serum, using a suspension of this organism as the antigen, showed strong specific precipitin lines. Negative control serum samples showed no reaction with either of these tests.

\section{Comment}

This patient is the first adult to be reported in Britain with septicaemia due to $K$ kingae. One adult has been reported on in the United States with clinical features due to Moraxella osloensis bacteraemia 